\title{
Using Participatory Rapid Appraisal and DPSIR approaches for participatory modelling: A case study for groundwater management in South Australia
}

\author{
${ }^{1,2}$ El Sawah, S., ${ }^{1,2}$ H. A. Guillaume, ${ }^{2,3}$ M. Mitchell \\ ${ }^{1}$ Fenner School of Environment and Society, The Australian National University, Canberra, Australia \\ ${ }^{2}$ National Centre for Groundwater Research and Training, The Australian National University, \\ Canberra, Australia \\ ${ }^{3}$ Charles Stuart University \\ Email: sondoss.elsawah@anu.edu.au
}

\begin{abstract}
Groundwater management faces a growing number of complexities and uncertainties including: the impacts of climate change, increasing demand, and socio-economic and ecological outcomes of management policies. To help deal with these issues, social learning is an interactive process which brings together scientists, policy makers, and stakeholder groups in order to share their views and develop a common framework for managing the system. This project aims to use a participatory modelling approach to support social learning about the future of groundwater management in South Australia. This paper reports on the data collection and analysis methods used in the scoping phase of the study. The central focus is on the process undertaken rather than the content of the results.
\end{abstract}

Keywords: social learning, participatory modelling, participatory rapid appraisal, DPSIR 


\section{INTRODUCTION}

Sustainable use of groundwater resources face a growing number of threats. Of great importance are the impacts of climate change and climate variability in effecting groundwater recharge, as are the impacts of increasing demand often from agriculture and/or urban development. The challenge in meeting such threats lies in the complexities, uncertainties, and trade-offs that groundwater management involves. Coping with complex challenges largely relies on the capacity of various stakeholders groups (e.g. users, policy makers, scientists) to integrate and share their local and expert knowledge, openly exchange their values and preferences, and negotiate options and estimate and afford costs. This process of management requires ongoing dialogues aimed at improving trust among stakeholders, promoting a shared understanding of what sustainable resource levels might be, and often leads to the development of collective policies and strategies that accommodate multiple values and interests. This process and subsequent outcomes are packaged in the term "social learning" (PahlWostl and Hare, 2004).

Modelling exercises can provide an environment (i.e. methods and tools) to facilitate the process and outcomes of social learning. From a modelling and software development perspective, getting endusers in the loop ensures that model outputs are relevant and credible. It may also increase users' sense of model ownership and likelihood for adoption. This helps bridge the well-cited gap between model design and use (McIntoch et al., 2008). Moreover, stakeholders and decision makers possess a wealth of local and experiential knowledge about the modelled system. Eliciting such knowledge may be valuable input to formulating model structure and covering missing information.

From a decision-making perspective, involving decision makers in the modelling process help improve their understanding about the complexities and uncertainties of managing the system. When stakeholder groups and policy makers have divergent, sometimes conflicting, views about problem causes, consequences and effective management policies, PM provides a learning-facilitated environment where people can mutually explore issues, formulate policies, and use the model as an aid for reflection and negotiation. This process helps promote a shared understanding of root issues, interactive communication, appreciation of other views and perhaps consensus-building. Active engagement of stakeholders in different modelling activities gives a unique opportunity for (Costanza et al., 1998):

- Eliciting and understanding the whole range of stakeholder values related to sustainable resource use;

- Embracing and communicating the complexity and scale of issues to stakeholders in a suitable format,

- Exposing the complexity underlying any decision by unraveling its social, economic, and social outcomes; and

- Identifying, assessing and communicating risks related to various types of uncertainty, including limitations of knowledge and inherent system uncertainties.

This approach of modelling with stakeholders is now well known as "participatory modelling" (eg Bousquet and Voinov, 2010). Accordingly, a participatory modelling project ideally includes four phases:

1. Scoping: in any project, scoping includes exploring the broad physical and social context of the study area, and defining the project's objectives and deliverables;

2. Framing: in this phase, modellers and relevant stakeholders work together to explore and structure various issues and viewpoints regarding the modelled system. This provides the basis for defining model purpose, use and functional requirements;

3. Modelling: this phase focuses on the technical aspects of the modelling process, including model selection, implementation, testing and, if required, user-interface development and

4. Model use: depending on the prior-defined use, users and/or developers interrogate the model, analyse outputs and derive conclusions. 
In this paper, we present a case study in which participatory modelling is used to promote social learning about groundwater management in South Australia. The paper reports on the data collection and analysis methods used in the scoping phase of the study. The central focus is on the process undertaken rather than the results.

\section{GROUNDWATER MANAGEMENT IN THE WILLUNGA BASIN}

The Willunga basin lies in the McLaren Vale Prescribed Wells Area (PWA). The McLaren Vale PWA is located in south of Adelaide and covers an area of approximately 320 kilometre-square (see Figure 1). It is a predominantly rural area where viticulture and tourism are the major industries. The groundwater system within the McLaren Vale PWA is a complex multi-aquifer system divided into four main aquifer units: Quaternary, Port Willunga Formation, Maslin Sands and fractured basement rock. The study area focuses on the Port Willunga Formation which provides a significant volume of the area's irrigation groundwater use.

In response to community concerns about unsustainable groundwater extraction rates (a range of 5-9 GL/year in the period 1990-2000) and increasing salinity levels, the McLaren Vale PWA was first licensed in 2000. The water allocation plan determines $6.6 \mathrm{GL} /$ year as the sustainable extraction rate (i.e. sustainable yield). Over the period 2000-2003, monitoring results showed a general reduction in the rate of decline of annual maximum groundwater levels. Over the same period, the annual maximum salinity fell in about half the observation wells and rose in the remaining wells. Several factors have contributed to improved groundwater quality, including: introducing water licensing, improved irrigation efficiency, and the occurrence of favourable climate conditions which affected groundwater recharge and relaxed pressure on groundwater use.

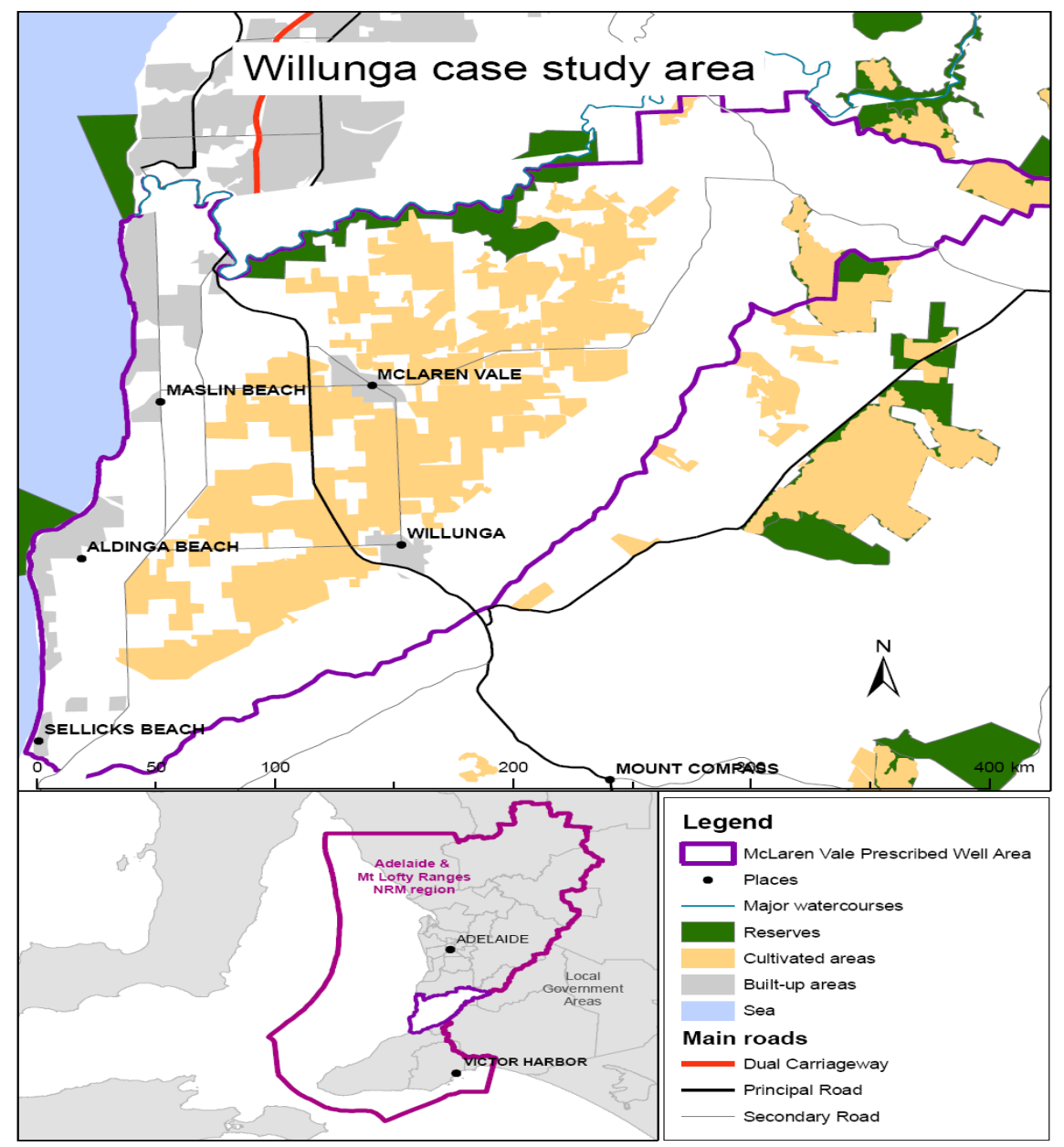

Figure 1: The study area (source: Geoscience) 


\section{THE NCGRT PROJECT IN THEWILLUNGA BASIN}

The National Centre for Groundwater Research and Training (NCGRT) funds research projects that aim to improve understanding and management of groundwater systems in Australia. The centre typically adopts a case study approach with the focus on selecting areas that may showcase the effectiveness of various research methods (including modelling/models) in tackling the complex and uncertain nature of issues surrounding groundwater management. One of the case studies covers the groundwater system in the Willunga basin area.

The objective of the Willunga project is to develop and evaluate a methodology (i.e. methods, models, tools) to promote social learning among policy makers and stakeholder groups for assessing sustainable groundwater yield options and the future of groundwater management in the area. The Willunga area was selected for several reasons. Firstly, the area is agriculturally productive but is threatened by urban encroachment. Secondly, the area requires innovative groundwater planning to deal with several issues (e.g. surface water-groundwater interconnections, quality and quantity issues, indigenous issues, climate change issues, water trading issues). Thirdly, the project is timely as it can effectively add valuable insights in development of the water plan in the region, thereby providing an opportunity to assist in generating successful project outcomes.

\section{EARLY STAKEHOLDER ENGAGEMENT: SCOPING PHASE}

\subsection{Participatory rapid appraisal approach}

In the scoping phase of modellers focus on collecting local system knowledge of the study area and related issues. This knowledge (mainly qualitative) help researchers "get a sense" of how the system works, and design project methods and outputs that are most appropriate to the study context. This includes identifying relevant project stakeholders. In our project, we had four initial objectives of the scoping phase:

1. Explore the Willunga Basin area in terms of its biophysical and socioeconomic settings;

2. Establish relationships with key stakeholders and interest groups;

3. Learn about the broad issues surrounding the groundwater system in the basin and

4. Understand the multiple views held by stakeholders, including their issues of concern, values, interests, and how they think about the future of the area.

We used a Participatory Rapid Appraisal (PRA) approach for data collection. PRA is a learning approach that allows researchers to collect and reflect on information through direct involvement with people in the area. It is a semi-structured approach which encompasses a wide range of methods (e.g. field trips, informal meetings, interviews, observation). Selection of appropriate methods depends on the information required and the local situation.

In October 2010, the research team conducted a four-day visit to the area generating a number of activities including field trips, informal/formal meetings, and semi-structured interviews. Table (1) lists the stakeholder groups and agencies along with the data collection method.

Before the visit, we prepared a list of broad questions about groundwater management in the area (e.g. what do you think about the health of the groundwater resource in the basin?). Questions were used to prompt rather than guide the discussion with interviewees and were adapted to fit the interviewees' background. After each interview, whenever possible, we reflected, reviewed and updated questions in light of responses. A crucial principle in PRA is continuous reflection and improvement as soon as new information becomes available.

Interviews and meetings were not recorded but notes were taken after gaining interviewees' consent. At the end of the visit, notes were collected and consolidated. The visit was wrapped up by a feedback session where we invited interviewees to share the visit's outcomes and sought their views about the project's objectives and future directions. We promised to send a feedback report. 
Table 1: Participants in scoping phase (Numbers between brackets denote the number of people from each group).

\begin{tabular}{|c|c|c|c|}
\hline $\begin{array}{l}\text { Organisation and number of } \\
\text { participants }\end{array}$ & Representation & $\begin{array}{l}\text { Role in groundwater } \\
\text { management }\end{array}$ & Research activity \\
\hline $\begin{array}{l}\text { Natural Resources } \\
\text { Management Board (2) }\end{array}$ & Government agency & $\begin{array}{l}\text { Responsible for designing } \\
\text { water allocation plans for } \\
\text { Mclaren Vale area, including } \\
\text { the engagement of the } \\
\text { community in water planning. }\end{array}$ & Meeting \\
\hline Onkangirina Council (3) & Government agency & $\begin{array}{lcr}\text { Responsible } & \text { for setting the } \\
\text { framework } & \text { for } & \text { water } \\
\text { management } & \text { policies } & \text { and } \\
\text { strategies. } & & \end{array}$ & Meetings \\
\hline Stock and domestic users (3) & Individual & 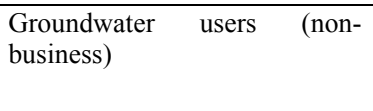 & $\begin{array}{l}\text { Semi-structured } \\
\text { interviews, informal } \\
\text { meetings }\end{array}$ \\
\hline Grape growers (3) & Individual & Groundwater users (business) & $\begin{array}{l}\text { Semi-structured } \\
\text { interview }\end{array}$ \\
\hline $\begin{array}{lll}\text { Willunga } & \text { Basin } & \text { Water } \\
\text { Company (1) } & & \end{array}$ & Private service provider & $\begin{array}{l}\text { The only company in the basin } \\
\text { which provides recycled water } \\
\text { for irrigation }\end{array}$ & $\begin{array}{l}\text { Semi-structured } \\
\text { interview }\end{array}$ \\
\hline Land care group (1) & Non-government organization & Environmental group & $\begin{array}{l}\text { Semi-structured } \\
\text { interview }\end{array}$ \\
\hline Willunga Basin Friends (3) & Non-government organization & Environmental group & Meeting \\
\hline Local expert (1) & Individual & $\begin{array}{l}\text { Participated heavily in } \\
\text { groundwater planning in the } \\
\text { area }\end{array}$ & Meeting \\
\hline $\begin{array}{l}\text { McLaren Vale Grape, Wine } \\
\text { and Tourism Association (3) }\end{array}$ & Non-government organization & $\begin{array}{l}\text { Community of grape growers } \\
\text { presenting wine marketing } \\
\text { services }\end{array}$ & Meeting \\
\hline
\end{tabular}

\subsection{Content analysis: DPSIR framework}

We analysed the collected data with the purpose of capturing the main issues surrounding groundwater management in the basin. A DPSIR (Drivers-Pressures-States-Impacts-Responses) framework was used. The framework provides guidance for identifying, structuring and representing these issues in terms of system elements and their interactions (Valkering et al. 2009).

The DPSIR framework was developed by the European Environment Agency (EEA) (OECD, 1994) to help identify sustainability indicators. It provides a systems approach for identifying, structuring and representing complex issues in terms of interactions between the system drivers, pressures, states, and responses. Drivers are the environmental and socioeconomic forces of change in the system. Pressures are the processes driven in effect to the interplay of these forces. For example, human activities drive the release of emissions and wastes to environmental systems. System states denote the dynamic internal bio-physical conditions. Impacts are the value-laden effects for the changes in the system states. Responses include institutional and individual management decisions and interventions.

(1) The analysis process followed two interactive steps. First, notes were scanned in order to identify, classify and group stakeholder's ideas and concepts into the following categories as defined in (Hoekstra, 1998): environmental drivers, socioeconomic drivers, hydrological state, water quality state, ecological impacts, socio-economic impacts, water policies, and individual (autonomous) responses. Second, the content of notes was carefully analysed using the identified concepts as sub-categories. A new sub-category/category was created for data that could not be fitted to an existing one. For example, some stakeholder's concerns about a number of indigenous-related effects did not fall into the categories ecological and socioeconomic impacts. Therefore, a new cultural impacts category was added. Table 2 shows 
examples of categories, sub-categories, and codes from the content analysis. Figure (2) is the DPSIR representation derived from the content analysis.

Table 2: Examples of the categories, sub-categories, and codes from the content analysis

\begin{tabular}{|c|c|c|c|c|}
\hline Category & $\begin{array}{l}\text { Environmental } \\
\text { Drivers/Pressures }\end{array}$ & Socio-economic Drivers/Pressures & Water state & $\begin{array}{l}\text { Socio- } \\
\text { economic } \\
\text { impacts }\end{array}$ \\
\hline Sub-category & Climate conditions & Economic conditions & $\begin{array}{l}\text { Groundwater } \\
\text { quality }\end{array}$ & $\begin{array}{l}\text { Economic } \\
\text { indicators }\end{array}$ \\
\hline Code & $\begin{array}{l}\text { Change in rainfall } \\
\text { patterns }\end{array}$ & AUD value & Salinity levels & Crop quality \\
\hline Quotes & $\begin{array}{l}\text { "It depends on how } \\
\text { severe and how long } \\
\text { the heat is. They can } \\
\text { handle a few days, but } \\
\text { if a heat wave is more } \\
\text { than 5 days, there } \\
\text { starts to be a problem" }\end{array}$ & $\begin{array}{l}\text { "The value of the Australian } \\
\text { dollar is probably even more } \\
\text { important than climate change, } \\
\text { given a lot of wine is for exports" }\end{array}$ & $\begin{array}{l}\text { "Salt water level, } \\
\text { the vineyards } \\
\text { cannot tolerate } \\
\text { it" }\end{array}$ & $\begin{array}{l}\text { "There is a } \\
\text { push for the } \\
\text { quality of } \\
\text { grapes because } \\
\text { it is a } \\
\text { depressed and } \\
\text { competitive } \\
\text { market" }\end{array}$ \\
\hline
\end{tabular}

\section{DISCUSSION AND NEXT STEPS}

Through our experience, we have found that PRA has several advantages that may contribute to the success of a participatory modelling project. Firstly, PRA emphasises interactive communication and building good relationships between researchers and local people. This is essential, especially in the early phases of the project, to help modellers frame the process in a way that is aligned with stakeholder preferences and needs. This also increases stakeholder willingness for participation. Secondly, the iterative and diversity-oriented nature of PRA promotes deep understanding of local knowledge which is instrumental for designing relevant and credible models (Voinov and Gaddis, 2008). Whereas PRA provides modellers with a "snapshot" about the broad issues related to the modelled system, we suggest it may not be appropriate beyond scoping to answer more focused issuesstructuring and analysis questions.

For a modelling purpose, using DPSIR for content analysis provides a framework for effective identification of the broader range of social, environmental, cultural and economic issues. This gives modellers an early glimpse of the main modelling components and data essential to link stakeholder views to modelling inputs, outputs and internal states. In addition, the DPSIR framework can be used to communicate with stakeholders about the modelling products and how their input feeds into the modelling process. However, some caveats need to be considered. Firstly, the definition and classification of elements according to DPSIR is influenced by the researcher's own perspective and interpretation of collected data. This also implies that some issues may be missing.. To account for this, the framework is regarded as a preliminary and working modelling artefact that will be further negotiated with stakeholders in the next phase of the project. Secondly, the framework is a high level system representation that does not show the detailed causal links between system elements. Whereas capturing these causal links is essential for scenario design and model construction, this conceptualization is sufficient given the early scoping phase. 


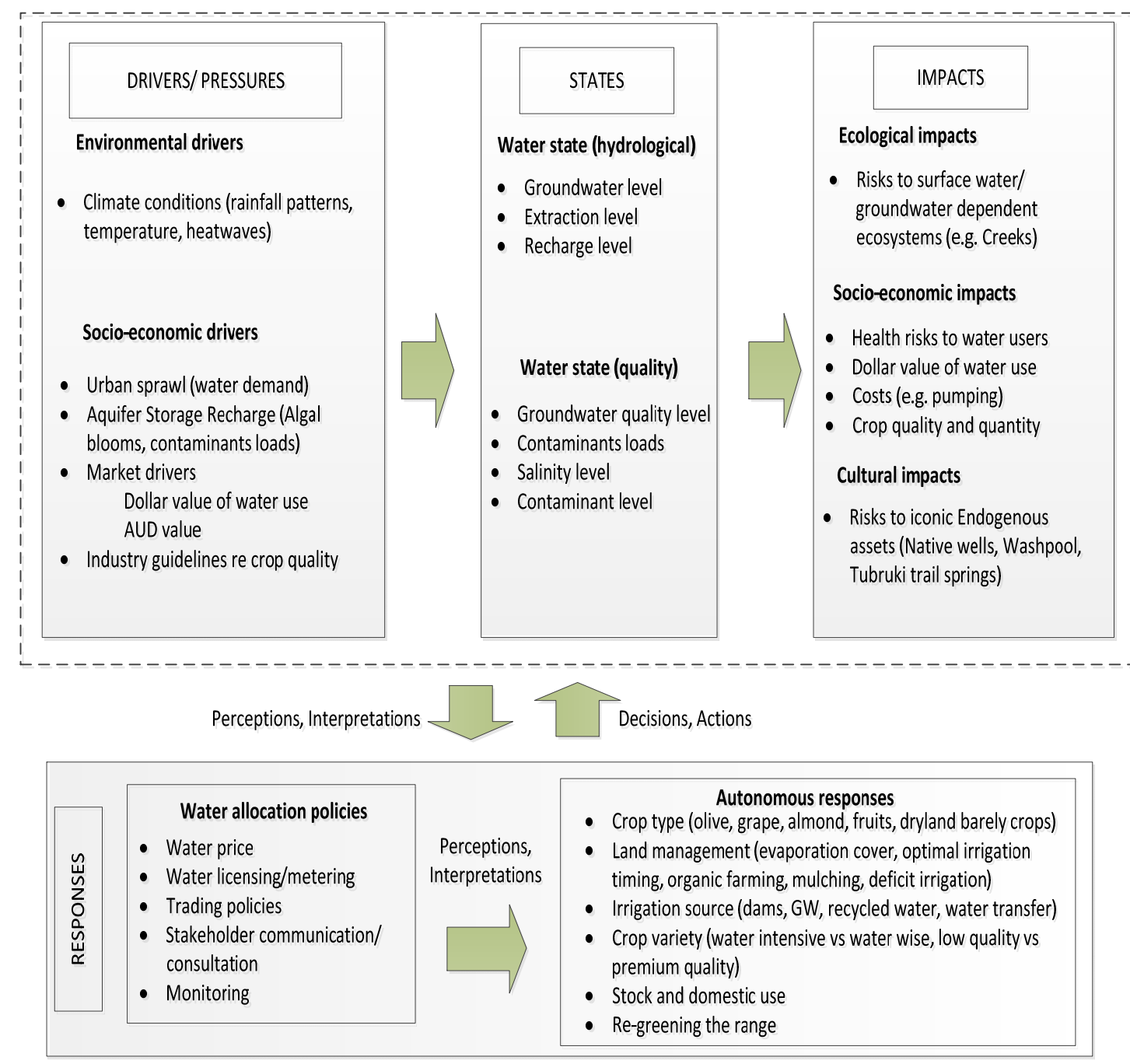

Figure 2: The DPSIR representation derived from the content analysis.

\section{References}

Hoekstra, A. Y. (1998). Perspectives on Water: An integrated model-based exploration of the future. International Books. Utrecht, The Netherlands.

Costanza, R. and Ruth, M. (1998). Using Dynamic Modeling to Scope Environmental Problems and Build Consensus. Environmental Management. 22 (2), 183-195.

OECD (1994). OECD Core Set of Indicators for Environmental Performance Reviews: A Synthesis Report by the Group on the State of the Environment. Organisation for Economic Co-operation and Development (OECD). Paris, France.

Pahl-Wostl, C. and M. Hare (2004). Processes of social learning in integrated resources management. Journal of Community \& Applied Social Psychology 14 (3),193-206.

Walz A, Lardelli, C., Behrendt, H., Gret-Regamey, A.Lundstrom, C., Kytzia, S. Bebi, P. (2007). "Participatory scenario analysis for integrated regional modelling", Landscape and Urban Planning, 81, 114-131.

Valkering, P., Tabara, J., Wallman, P. and Offermans, A. (2009). Modelling Cultural and Behavioural change in Water Management: An integrated, agent based gaming approach. The Integrated Assessment Journal. 9 (1), 19-46.

Voinov, A. and Brown Gaddis, E. (2008). "Lessons for successful participatory watershed modeling: A perspective from modeling practitioners”, Ecological Modelling, 216, 197-207. 